Organo- and

\title{
Tripeptides: Efficient Catalysts for 1,4-Addition Reactions to Nitroolefins
}

Key words

1,4-addition reaction

nitroolefins

peptides

enantioselectivity

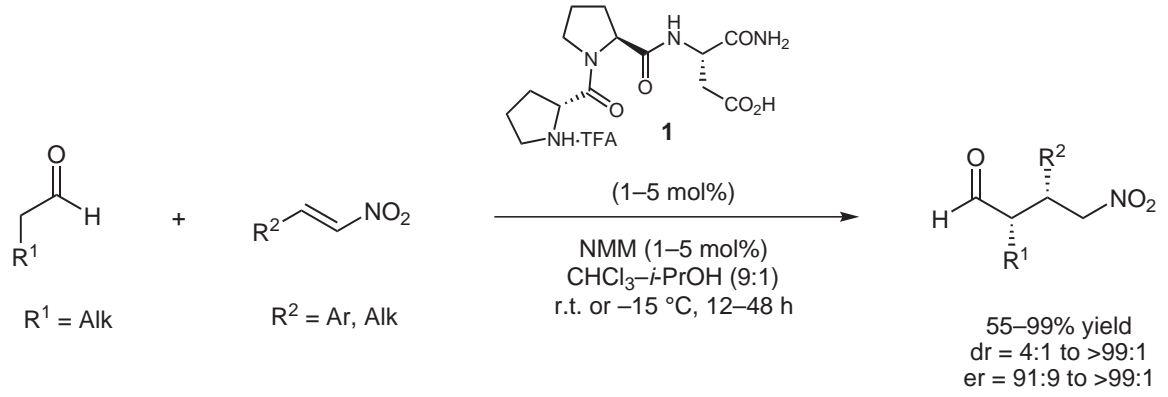

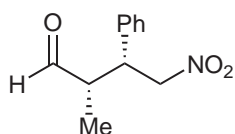

$70 \%$ yield $\mathrm{dr}>99: 1$ er $=98: 2$<smiles>O=CC(C[N+](=O)[O-])[C@H](C=O)c1cccs1</smiles>
$94 \%$ yield
$\mathrm{dr}=30: 1$ $\mathrm{dr}=30: 1$
er $=98: 2$<smiles>O=CC([Al])[C@@H]([O-])C[N+](=O)[O-]</smiles>

er $=99: 1$
Significance: The authors designed tripeptide 1 as an efficient organocatalyst for the asymmetric conjugate addition reactions between aldehydes and nitroolefins. The authors have used $N$-methyl morpholine (NMM) as an additive for this reaction. After screening different solvents, a mixture of $\mathrm{CHCl}_{3}$ and $i-\mathrm{PrOH}(9: 1)$ has been found to be the best solvent for this reaction. With $1-5 \mathrm{~mol} \%$ of catalyst 1, good to high diastereoselectivities ( $\mathrm{dr}=$ $4: 1$ to $>99: 1$ ) and excellent enantioselectivities (er $=91: 9$ to $>99: 1$ ) were obtained for different aldehydes and nitroolefins.
Comment: Recently, organocatalytic asymmetric conjugate additions between aldehydes and nitroolefins have been reported by several groups (see reviews below). This method as reported by the present authors is attractive because of its low catalyst loading (down to $1 \mathrm{~mol} \%$ ).

Reviews: S. B. Tsogoeva Eur. J. Org. Chem. 2007, 1701; S. Sulzer-Mossé, A. Alexakis Chem. Commun. 2007, 3123. 